DOI 10.31489/2021No3/76-82

UDC 62-932.2, 62-1/-9

\title{
DEVELOPMENT OF THE BIOGAS INDUSTRY AND PROSPECTS FOR THE IMPLEMENTATION OF BIOGAS PLANTS IN KAZAKHSTAN
}

\author{
Abilmazhinov E.T., Akimzhanov A.Zh., Shaiakhmetov E.Y.*, Anibaev S.N., Nurgaliyev N.N., \\ Shakerkhan K.O., Sailauov D.M.
}

Shakarim University of Semey, East Kazakhstan region, Semey, Kazakhstan, shaiakhmeterzh@mail.ru

\begin{abstract}
The article provides an overview of biogas technologies abroad and in Kazakhstan, the experience of foreign countries in the biogas industry, the development and prospects for the introduction of biogas plants in the Republic of Kazakhstan for the environmentally friendly and profitable processing of organic agricultural waste, food production, processing enterprises. Recommendations are given on the specifics of the design of biogas plants in the difficult climatic conditions of Kazakhstan (especially in the north, east and central Kazakhstan). The current design of a biogas plant (filling volume $3.7 \mathrm{~m}^{3}$ ) is shown, in the design of which units of our own design were used, this is a peristaltic pump and a raw material grinder. The efficiency of a number of units, in particular a new design peristaltic pump, was shown in the course of the experiments.
\end{abstract}

Keywords: renewable energy sources, biomass, biogas, biogas plant, biofertilizer.

\section{Introduction}

Environmental pollution in the world has become rampant, therefore many countries, under pressure from the public, environmental organizations, are fighting harmful emissions, environmentally dirty industries. At the end of 2019, renewable energy sources showed good growth, wind energy reached (5.44\%), solar energy (2.71\%), biomass and waste (2.24\%) and "other renewable energy sources" $(0.4 \%)$ of the total electricity generation in the world [1]. In 2020, the 27 countries of the European Union received more electricity from renewable sources than from fossil fuels for the first time. The share of coal, gas and oil decreased to $37 \%$, while wind, sun, hydropower and biomass provided $38 \%$ of the total generation in the EU, increasing production by $10 \%$ [2-6].

It is most correct to evaluate and compare the cost of electricity obtained by different methods using the EROI (energy returned on energy invested) indicator - the ratio of energy received from a source to the amount of energy spent on its receipt. For example, EROI 20: 1 for a certain type of fuel means that from each consumed $\mathrm{kWh}$ it is possible to generate $20 \mathrm{kWh}$ [7]. The hydroelectric power plant has the highest EROI, close to 100: 1. For coal and gas fired power plants, EROI ranges from 30: 1 to 75: 1. For renewable energy sources (except for hydro resources), the indicators are as follows: for wind power plants EROI reaches a maximum of 16: 1, for solar power plants a maximum of 3.8: 1 [7].

One of the types of renewable energy sources is biogas (purified biomethane), obtained by anaerobic methane fermentation of biomass, i.e. organic waste from agriculture and processing plants, etc. The advantage of using biomass energy by methane fermentation (as opposed to solar and wind energy) is independence from meteorological conditions, i.e. continuity and stability in energy use, a high EROI from 30: 1 to 75: 1 (depending on raw materials, technology perfection, climatic conditions, the degree of biogas purification and the volume of the bioreactor), additional income from the obtained biofertilizers and solving the ecological problem of waste and pollution environment. Biogas production prevents methane emissions into the atmosphere [3]. According to forecasts, the contribution of biomass as an additional source of energy by 2020 will reach $23.5 \%$ of the total energy consumption in the world [8].

The aim of the work is to create a relatively inexpensive, efficient and adapted to the conditions of work in the region (in our case, East Kazakhstan) industrial biogas plant, which is quite relevant. The practical significance and novelty of the developed design of the biogas plant is the use of auxiliary units of our own design, since the use of foreign analogues leads to a significant increase in the cost of the installation, this is the design of the peristaltic pump and the design of the raw material grinder being developed. The efficiency 
of a number of units, in particular a peristaltic pump of a new design, was shown on the created bioreactor unit (Figure 1), with a total volume of the bioreactor $V=4.62 \mathrm{~m}^{3}$.

The next stage of our work (it is planned to show at the end of the work in a separate article), the creation of an industrial underground biogas plant (based on climatic conditions) for peasant farms with the further use of the obtained gas for generating electricity and use in everyday life, which would solve the problem of distant farms in providing own electricity and heat.

\section{Contents and methods. The use of biogas technologies abroad}

The leaders in biogas production are the countries of the European Union (EU). In European countries, $75 \%$ of biogas is obtained from agricultural waste, $17 \%$ - from organic waste from private households and enterprises, another $8 \%$ - from wastewater (installations in sewage treatment plants). Denmark is the leader in the use of biogas: this type of fuel provides almost $20 \%$ of the country's energy consumption. [8-12].

Asian countries (China, India, Nepal, etc.) are the leaders in the world in terms of the number of functioning BGS, including mini-installations. In Africa and Asia, the bulk of biogas is produced from food waste, as well as from human waste (sewage). There are about 2 million biogas plants operating in African countries, which provide gas to more than 10 million people [10].

In Latin America, Brazil and Argentina are among the leading countries in the world in terms of the number of vehicles fueled by biogas. In 2010, a social project Biobolsa was launched in Mexico, which provided local farmers with inexpensive biogas plants; this project is actively developing in 9 countries of Latin America and Africa [13, 14]. The biogas market in the USA is much smaller than in Europe. Despite the presence of a large number of farms, there are only about 200 biogas plants operating on the waste of agricultural complexes on the territory of the country. At landfills, the United States is actively introducing technology for producing landfill gas, collecting and disposing of landfill gas [8-10]. In the CIS countries, biogas plants are being actively introduced in Ukraine, Belarus, Kyrgyzstan, and the Russian Federation. In Uzbekistan, at present, biogas plants (BGU) have been introduced in 45 farms with a total annual capacity of 1.1 million cubic meters of biogas [15]. Large BGS are designed mainly according to individual projects, depending on the type of raw materials (vegetable, industrial waste or animal husbandry waste), its quantity and the purpose of gas production (energy production, heating).

In the USA, Europe, the CIS countries (Ukraine, Belarus), they mainly use the designs of European manufacturers, these are large vertical aboveground reactors (due to climatic conditions), insulated, heating the reactor using a heat exchanger, heat is generated on the produced gas, the operating mode is thermophilic (for example, Swiss firm Zorg Biogas BMGH). In the countries of Asia, Africa, Latin America, along with large biogas plants, there are many small and medium biogas plants designed for small farms. The designs of small (gas production from $2 \mathrm{~m} 3$ ), often artisanal biogas plants differ in variety (vertical, horizontal, without mixing, etc.) and are made of improvised material (brick, plastic, rubber, metal), the temperature regime is psychophilic or mesophilic. However, there are a number of common features, these are mainly aboveground (or buried), non-insulated structures, with a vertical or horizontal reservoir (in a number of small biogas plants, the reservoir is a rubber or plastic bag, for example, according to the Biobolsa program in Latin America). Basically, China occupies the niche of selling small biogas plants [10, 13, 14].

\section{Development and prospects for the introduction of BGP in Kazakhstan}

The process of introducing BSU in the Republic of Kazakhstan is at the initial stage of its development. One of the successful BSU projects for generating electricity from the waste of a pig-breeding complex was implemented in the Zhambyl region. The daily productivity of biogas is 5300 cubic meters per day [16]. In the village of Vostok, Kostanay region, biogas and electricity were obtained on an industrial scale (the date of the launch of the biogas plant is 12/31/2009). All equipment for biogas and electricity production was designed and supplied by Zorg Biogas Ukraine. The biogas station, consisting of 2 reactors of $2400 \mathrm{~m} 3 \mathrm{each}$, has been brought to full capacity; it is planned to receive 3 million kWh of electricity from biogas annually. The raw material for the station is manure from large and small livestock, as well as grain waste. The cost of the biogas plant is 400 million tenge [16].

In the East Kazakhstan region, in the village of Privolnoye, a biogas plant operates on the basis of the Bagration farm, which allows to process 10 tons of manure per day and produce 400 cubic meters of biogas [16]. In November 2017, in Shymkent, the first biogas plant with a capacity of $0.5 \mathrm{MW}$ was launched in Central Asia. In the complex of this biogas plant, new technologies of the Czech company HEDVIGA 
GROUP are used - the production of heat and electricity by treating wastewater from the city's treatment facilities and extracting biogas from it ( $300 \mathrm{~m} 3$ / day). The total cost of the project is 2 billion 200 million tenge [17].

In 2018, in the village of Kurminskoye, Abay district, Karaganda region, the poultry farm launched a biogas station for processing poultry manure. The cost is 573 million tenge, modern European equipment has been installed. Capacity - 8,800,000 kWh of electricity, over 18 thousand tons of biofertilizers per year, up to 23 thousand cubic meters are produced daily. $\mathrm{m}$ of biogas. The enterprise processes about 150 tons of poultry waste per day and produces about 14 thousand $\mathrm{kWh}$ of electricity from biogas [18].

In the North Kazakhstan region, a biogas plant is under construction for processing up to 40 tons of poultry farm waste per day with obtaining up to $9500 \mathrm{~m} 3$ / day of biogas, $1 \mathrm{MW}$ electricity and biofertilizer. The equipment was supplied by the Russian company "AgroBioGas", the cost of the construction of the biogas plant is US \$ 3 million [19]. They want to implement a similar project on the basis of the UstKamenogorsk poultry farm in East Kazakhstan region [20].

Of the operating small biogas plants in the Republic of Kazakhstan, it is necessary to mention the installations of Samat Abenov (director of FE "Abenov"). The inventor made 4 experimental industrial prototypes. The biogas production process at one of the plants with a daily volume of $5 \mathrm{~m} 3$ is fully automated. Biogas is used by an entrepreneur for his own needs, and biofertilizers are sold at a bargain price to peasant farms (Enbekshi settlement, Talgar region, near Almaty) [21].

Anaerobic processing of manure four times - in comparison with unfermented manure - increases the content of ammonium nitrogen $(20 \div 40 \%$ of nitrogen goes into the ammonium form). The assimilable phosphorus content doubles to $50 \%$ of the total phosphorus. In addition, during fermentation, weed seeds, which are always contained in manure, are completely killed, microbial associations, helminth eggs are destroyed, an unpleasant odor is neutralized, i.e. the required ecological effect is achieved [23]. When comparing biofertilizers with other types of fertilizers, we have the following quality indicators [24] (table 1). Comparison of biofertilizers and other fertilizers by value [24] (table 2).

Table 1. Comparison of quality indicators of biofertilizers with other types of fertilizers

\begin{tabular}{|l|c|c|c|}
\hline Indicators & Biofertilizers & Mineral fertilizers & $\begin{array}{c}\text { Organic fertilizers } \\
\text { (manure, droppings) }\end{array}$ \\
\hline Assimilation by plants, \% & 100 & $35 \div 40$ & 80 \\
\hline Nitrogen loss, $\%$ & $5 \div 8$ & 50 & 30 \\
\hline Nitrate content in products & - & + & - \\
\hline Leaching from the soil, $\%$ & 15 & 50 & 80 \\
\hline
\end{tabular}

Table 2. Cost indicators of biofertilizers and other fertilizers (in tenge)

\begin{tabular}{|l|c|c|c|}
\hline Fertilizers & Application rate, $\mathrm{kg} / \mathrm{ha}$ & Cost, tenge / kg & Total cost, tenge / ha \\
\hline Mineral fertilizers & 300 & 64 & 19200 \\
\hline Manure & 6000 & 1,2 & 7200 \\
\hline Biofertilizers & 3000 & 0,8 & 2400 \\
\hline
\end{tabular}

Thus, biofertilizers are 8 times cheaper than mineral fertilizers, and 3 times cheaper than manure when applied per hectare, not to mention the quality indicators indicated above. As we see in Kazakhstan, all large biogas plants are mainly designed by European and Russian companies, however, the segment of medium (filling $15-55 \mathrm{~m}^{3}$ ) biogas plants for peasant farms is practically not involved. China is present in this segment, but Chinese biogas plants are not always suitable for the harsh continental climate of Kazakhstan, and the development of a domestic heated biogas plant with an underground location of the reservoir is necessary. Thus, the object of research is a domestic biogas plant, raw material cattle manure. Anaerobic processing of biomass was carried out at a biomass plant with a reversible peristaltic pump and grinder. The biogas yield was determined according to generally accepted methods. 


\section{Discussion of results}

Researchers of the scientific department "Natural Science and Engineering" of the University of Shakarim in Semey designed and then manufactured at the plant LLP "Metallist" (Semey, East Kazakhstan region) and successfully tested an industrial complex biogas plant with a wind turbine.

The installation (Figure 1) is automated, with a total volume of the bioreactor $\mathrm{V}=4.62 \mathrm{~m} 3$ (filling volume Vfill $=0.8, \mathrm{~V}=3.7 \mathrm{~m} 3$ ), can process $158.6 \mathrm{~kg}$ of fresh cow manure (or other organic waste) daily after the biogas plant enters the mode (mesaphilic, 16 days after the first loading) with the production of about $8 \mathrm{~m} 3$ and more biogas per day, after purification in columns and filters (biogas purification system) about $5 \mathrm{~m} 3$ of biomethane (more than 90\% CH4). This BGP is protected by the RK patent No. 32805. The difference between this unit is the use of a peristaltic pump with a grinder (protected by RK patents No. 31872 and No. 33061), instead of a recirculation pump with a hydrocyclone to provide a lighter mode of mixing the biomass. The developed pump design has shown its energy efficiency in the course of experiments in comparison with foreign analogues (table3) [25-27].

Table 3. Comparative characteristics of peristaltic pumps

\begin{tabular}{|l|l|c|c|c|}
\hline \multirow{2}{*}{ No. } & \multirow{2}{*}{ Description } & \multicolumn{2}{|c|}{ Foreign analogues } & \multirow{2}{*}{ Proposed design } \\
\cline { 3 - 4 } & & HCT-25-110 & $\Pi$ IH-15-1,5/,5,5 & \\
\hline 1 & Hose diameter & 25 & 15 & 50 \\
\hline 2 & Electric motor power, $\mathrm{kW}$ & 1,5 & 0,75 & 0,75 \\
\hline 3 & Pump rotor speed, rpm & 60 & 35,5 & $0-80$ (adjustable) \\
\hline 4 & Productivity, m3 / hour (liter / hour) & $1,32(1320)$ & $1,2(1200)$ & $2,2(2160)$ \\
\hline 5 & Maximum pressure, kg / cm2 & 12 & 4 & - \\
\hline 6 & Specific electricity consumption & 0,88 & 0,625 & 0,341 \\
\hline 7 & Cost, thousand tenge & 700,000 & & 299,700 \\
\hline
\end{tabular}

Currently, biogas plants are not mass-produced in Kazakhstan, but large industrial installations on the market are mainly of foreign production and rather expensive, meanwhile the number of livestock and poultry in the country is increasing annually [28], and agricultural waste is a stable source of biomass. The annual output of livestock and poultry waste by dry weight is 22.1 million tons, or 8.6 billion $\mathrm{m} 3$ of gas (gas consumption - 13 million tons, sheep - 6.2 million tons, horses - 1 million tons), plant residues - 17.7 million tons (wheat - 12 million tons, barley - 6 million tons, or 8.9 billion $\mathrm{m} 3$ ), which is equivalent to $14 \div 15$ million tons of standard fuel, or 12, 4 million tons of fuel oil, or more than half of the volume of oil produced [29]. Currently, the following features and prerequisites for the development of the biogas industry in Kazakhstan have developed:

- Kazakhstan occupies the second place in the CIS in terms of area and the ninth in the world, while the total population is 18.833 million people (data as of November 1, 2020), therefore, there are no problems with land areas to increase the size of biogas plant in width and length for farms.

- The climate in Kazakhstan is sharply continental, average temperatures in January are from minus 18 ${ }^{\circ} \mathrm{C}$ in the north to minus $3{ }^{\circ} \mathrm{C}$ in the south, the average July temperature is from $+19{ }^{\circ} \mathrm{C}$ in the north to + $29^{\circ} \mathrm{C}$ in the south. The lowest temperatures: up to minus $45^{\circ} \mathrm{C}$ in the north, east and central part, up to minus $30^{\circ} \mathrm{C}$ in the south. Daily drops can reach $20^{\circ} \mathrm{C}$ [22]. From the point of view of energy efficiency, it is more profitable to introduce bioreactor units in the south (as in the whole world), and in the north, east and central part of the Republic of Kazakhstan, special attention should be paid to thorough and thorough thermal insulation of bioreactors (methane tanks), to locate bioreactors indoors or underground.

- In the south of Kazakhstan, due to the rapid development of greenhouses, there are no problems with the sale of biofertilizers at a favorable price. In addition, in the south, it is beneficial to combine biogas with greenhouses for farms, and use biogas for their own needs, since it is problematic to sell it at a low price of natural gas (methane), with the exception of non-gasified areas.

- Agricultural lands of Kazakhstan occupy 222.998 million hectares [30]. The presented data show not only the huge potential of biomass, but also the potential for the use of biofertilizers, taking into account in this regard the program for the development of saline soils in Uzbekistan. 
- RK is a manufacturer (and from its own resources) of metal products, building materials (including cement, gravel, crushed stone, bitumen, etc.) required for the manufacture of biogas plants and biogas equipment.

- In the Republic of Kazakhstan (in particular in the East Kazakhstan region), deposits of zeolite ores are being developed, including the production of zeolite, a valuable natural material for cleaning and drying biogas.

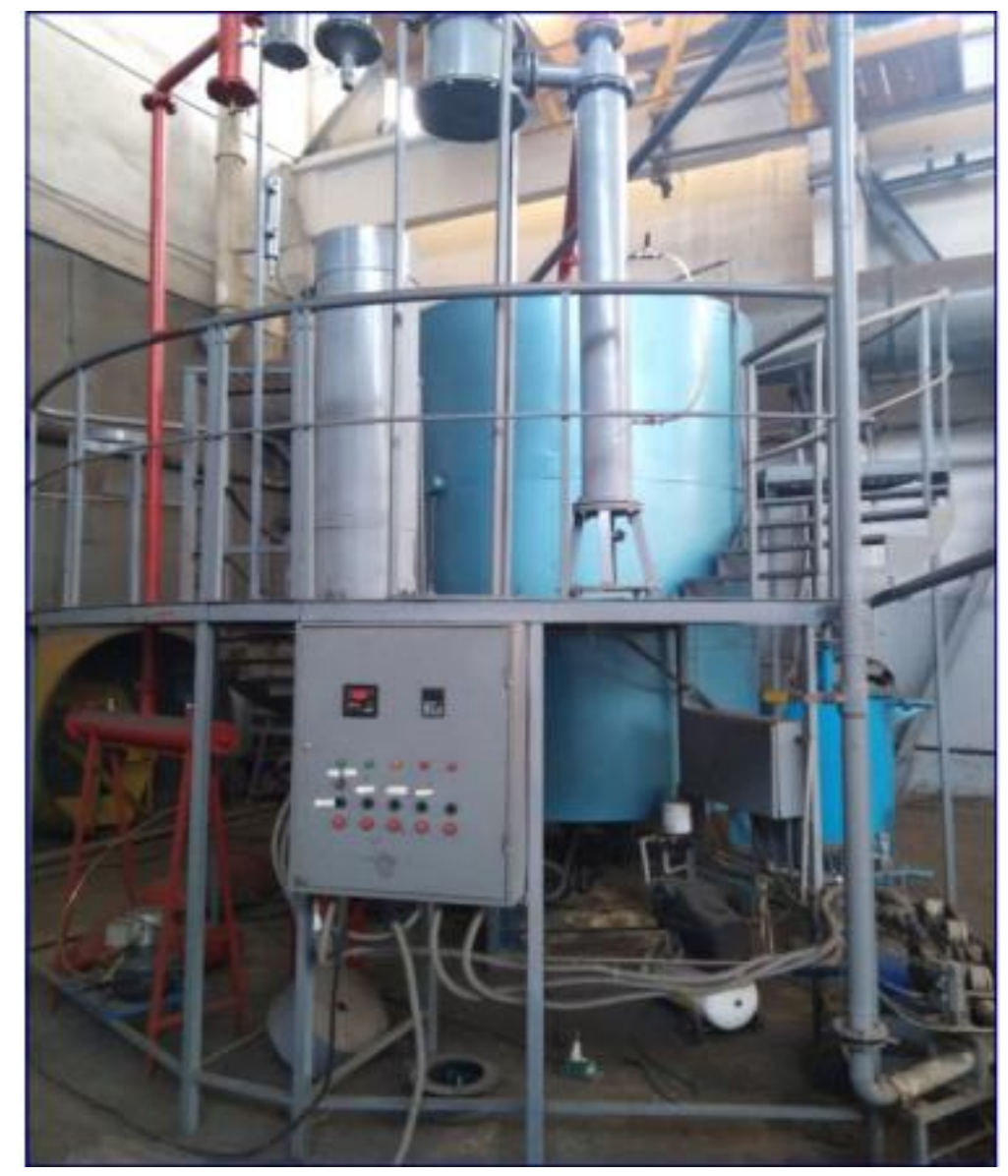

Fig.1. Industrial complex biogas plant of our own design.

It should be noted that most suppliers of bioreactor plants abroad (including the Russian Federation) [29] and individual entrepreneurs in the Republic of Kazakhstan widely advertise and sell bioreactor plants (moreover, it is expensive, about USD 1300 per $1 \mathrm{~m}^{3}$ of bioreactor), not including an important and necessary for the normal implementation of the technological process, equipment as a raw material grinder. The fact is that there is a noticeable amount of fibrous part in the manure, which clogs pipelines and pumps with poor-quality grinding, contributes to the formation of a crust in the bioreactor, prevents the normal release of biogas, and increases the time of methane fermentation. The designs of grinders developed by the staff of the scientific department of the University of Shakarim are effective, practical and inexpensive in comparison with foreign counterparts (for example, a similar German grinder costs about 13,000 euros). Also not included in the kit in most cases, the biogas purification system and other equipment.

\section{Conclusion}

1. Kazakhstan has the potential and rich raw material base for the development of the biogas industry;

2. From the point of view of manufacturing, energy efficiency, reliability, ease of operation, maintenance, repair and low price (relative to the one offered on the market) in the Republic of Kazakhstan, it is more promising to introduce biogas plant of its own domestic developments from domestic (local) materials. These are installations of our own design with horizontal underground concrete or steel bioreactors 
with thermal insulation, a heating system installed in the lower part of the concrete housing (for concrete) or in the form of a thermal jacket (for steel), with mobile submersible mixers made of corrosion-resistant materials with a sealed drive design, with a complete set of domestic technological equipment (a raw material grinder, a receiving tank with a mixer, pumps, instrumentation and automation, electrical equipment, pipeline fittings, connecting pipes and hoses, a water seal with a water indicator, a biogas purification system, a compressor for biogas injection, a gas holder).

3. These installations are obtained in the price range from 280 US dollars per $1 \mathrm{~m} 3$ of bioreactor volume of bioreactor, for installations with a volume of $250 \mathrm{~m} 3$ and more; for a bioreactor bioreactor volume of 50 $\mathrm{m} 3$ and more, the price is up to 480 US dollars per $1 \mathrm{~m} 3$ (for smaller volumes of bioreactor bioreactor it is more expensive), which makes them competitive in the market and enables a quick payback (no more than 2 years).

4. It is necessary to introduce in the biogas industry of the Republic of Kazakhstan biostimulants of our own domestic developments based on natural Kazakhstani raw materials to increase the yield of biomethane and reduce the time of methane fermentation.

5. Biofertilizers obtained as a result of methane fermentation should be used to improve and increase soil fertility of agricultural lands, expand greenhouse farms, to create a Kazakhstani market for biofertilizers, which is necessary for a short payback period for the introduced biofertilizers, as well as for the production of feed supplements.

\section{Acknowledgments}

This research has been is funded by the Science Committee of the Ministry of Education and Science of the Republic of Kazakhstan (Grant No. AP09259846)

\section{REFERENCES}

1 Ember UK think tank report. The share of renewable energy sources exceeded $8 \%$ in the share of the world energy. Available at: https://eenergy.media/2020/03/11/dolya-vie-prevysila-8-v-dole/ (March11, 2020).

2 Presentation by European think tanks Ember and Agora Energiewende, Renewable energy became the main source of electricity in the EU in 2020, the share of gas increased. Available at:https://www.dw.com/ru/vije-teperglavnyj-istochnik-jelektrichestva-v-es/a-56339064 (January 25, 2021).

3 Alekseenko S., Non-traditional energy. The Great Russian Encyclopedia. 2006, Vol.35, pp. 166 - 169.

4 Mibach E., Elkina A. Germany is breaking records in "green energy": what is behind it. 2019. Available at: https://www.dw.com/ru

5 Enerdata logo World Energy Statistical Yearbook 2020. Share of renewable energy sources in electricity generation. Available at: https://yearbook.enerdata.ru/renewables/renewable-in-electricity-production-share.html (December11, 2020).

6 UN Secretary General's report (26.08.2019), The growth of renewable energy sources cannot be stopped Available at: https://news.un.org/ru/story/2019/08/1361871.

7 Toshiba Blog. Why does green energy have a difficult future? Available at: https://habr.com/ru/company/ toshibarus/blog/481764/ (May15, 2019).

8 Gromova U. Biogas - an alternative fuel of the future Available at: http://www.solidwaste.ru/publ/view/ 581.html (August13, 2012).

9 Matthew R. Allen, et al. Trace Organic Compounds in Landfill Gas at Seven U.K. Waste Disposal Sites. Hills Environmental Science \& Technology 1997, Vol.31, No.4, March 1997 DOI: 10.1021/es9605634

10 Kurnakova N.Yu., Katolichenko D.S., Sukharev O., Volkhonsky A.A. Analysis of the development of bioenergy fuel production. Fundamental research. 2016, 268 p.

11 Scarlat N., et al. Biogas: Developments and perspectives in Europe. Renewable Energy. 2018, Vol.129, Part A, pp. $457-472$.

12 Cucchiella F., et al. An economic analysis of biogas-biomethane chain from animal residues in Italy. Journal of Cleaner Production. 2019, Vol. 230, 888 p.

13 Zalevski M. Biogas plants that provided energy for more than 3000 families in Latin America. Available at: https://medium.com/@ rodovidme (February8,2020).

14 Vinicius J., et al. Potential impacts of vinasse biogas replacing fossil oil for power generation, natural gas, and increasing sugarcane energy in Brazil. Renewable and Sustainable Energy Reviews. 2021, Vol. 135, pp. 110 - 118.

15 Report of the United Nations Economic Commission for Europe, PT Prospects for the development of biogas technologies in Uzbekistan Available at: https://www.unece.org (May 8, 2011).

16 Information agency inbusiness.kz, Where else in Kazakhstan do biogas plants work. Available at: https://inbusiness.kz/ru/post/gde-eshe-v-kazahstane-rabotayut-biogazovye-ustanovki (October21, 2020) 
17 Communication research agency Neftegaz.RU, Kazakhstan launched the first biogas plant in Central Asia with a capacity of $0.5 \mathrm{MW}$. Available at: https://neftegaz.ru (December14, 2017)

18 News agency baigenews.kz, In the Karaganda region, light is obtained from chicken droppings. Available at: https://baigenews.kz/special/pyat_initsiativ_prezidenta/v_karagandinskoi_oblasti_iz_kurinogo (October15, 2018)

19 News agency baigenews.kz, Biogas plant operating on waste from a poultry farm is being built in North Kazakhstan region. Available at: https: //baigenews.kz/news/v_sko_stroyat_biogazovuu_ustanovku _rabotaushchuu na_othodah_ptitsefabriki/ (September25, 2017)

20 Mikheeva N., East Kazakhstan: Biogas from poultry manure is not worse than from manure. Available at: https://kazakh-zerno.net/134722-vostochnyj-kazakhstan-biogaz-iz-ptichego-pometa-ne (October 11, 2017)

21 Kalimova A., Farmer from the Almaty region has developed a unique biogas plant. Available at: https://kazpravda.kz/ (March11, 2019)

22 Lasunjv N. Prospects for the use of a mobile biogas plant on a railway track in the climatic conditions of Kazakhstan. Available at: http://tekhnosfera.com/perspektivy-ispolzovaniya-mobilnoy-biogazovoy ustanovki-na zhele znodorozhnom-hodu-v-klimaticheskih-usloviyah-kazahstana (September15, 2015)

23 Rodina E., et al. Use of methane emissions from waste for biogas production. Bulletin of the KRSU. 2003, Vol.1, No. 6, pp. $65-72$.

24 Skbvatra service company website. The concept of biofertilizers. Available at:https://skbvatra.com.ua/ informatsiya/ispolzovanie-digestata-v-kachestve-udobrenij/ (September 23, 2017)

25 Anibaev S., et al. Biogas plant. Patent RK No. 32805, 2018, 7 p.

26 Anibaev S., et al. Peristaltic dosing pump, Patent for invention No. 31872, 2017, 6 p.

27 Serikkaliuly A., et al. Working tube of the peristaltic pump, Patent RK No. 33061, 2018, 8 p.

28 Ministry of Agriculture of the Republic of Kazakhstan. Available at: https://moa.gov.kz/ru/documents/2 (March 23, 2020)

29 Biogas plants for gas production. Available at: https://greda.kz/p59616395-biogazovye-ustanovki-dlya.html (September 11, 2020)

30 Mustafaev Zh.S. Reclamation of agricultural land in Kazakhstan: development, analysis and assessment. Environmental management. 2017, No. 1, p. 87. 